\title{
EL ROSTRO Y LA MASCARA: ENTREVISTA CON SERGIO PITOL
}

\author{
POR \\ EFRAIN KRISTAL \\ Harvard University
}

El origen de esta entrevista que le hice a Sergio Pitol en Praga, en el mes de junio de 1986, es una historia que se remonta a abril de 1981, cuando el notable narrador mexicano, hoy embajador de su país en Checoslovaquia, vino por primera vez a California para participar en un coloquio organizado por el profesor José Durand en la Universidad de Berkeley. En ese coloquio yo era uno de los voluntarios encargados de facilitar el transporte a los escritores. Fue así como un grupo de estudiantes de las universidades del norte de California tuvimos la oportunidad de charlar informalmente con algunos notables escritores, tales como Alfredo Bryce Echenique, Augusto Monterroso y Elena Poniatowska, y con otros como Sergio Pitol, que desconocíamos, pero que íbamos a leer con gran interés en el futuro.

Mientras que la mayoría de los participantes hablaron de su propia obra, Sergio Pitol hizo un homenaje a Alfonso Reyes. Su ponencia, diáfana, elogiosa y bien informada, explicaba la importancia de Reyes para la cultura mexicana. En ella, sin embargo, no se advertía la excelencia creativa del escritor que estaba hablando. La modestia de Sergio Pitol, como la de su contemporáneo y amigo José Emilio Pacheco, ha precluido que adquieran la fama, a corto plazo, que van a lograr necesariamente.

Me empecé a dar cuenta de su erudición literaria cuando lo llevé de Berkeley a San Francisco, ciudad que él iba a visitar por primera vez. Le hablé de los libros que estaba leyendo en ese momento. Sobre todos ellos tenía datos y anécdotas esclarecedores. Le conté de una monografía que estaba escribiendo sobre Las olas de Virginia Woolf, para el curso del profesor René Girard en Stanford, y me hizo observaciones iluminantes. Meses después me enteré de que las mejores traducciones al 
español de Woolf y otros escritores anglosajones como Henry James, Jane Austen, Joseph Conrad y Malcolm Lowry son las suyas. Nuestra conversación terminó cuando me pidió que lo dejara en una sección de San Francisco, que yo desconocía, donde había librerías especializadas en idiomas eslavos.

Al día siguiente los llevé a él, a Elena Poniatowska y a María Luisa Puga a pasear por los bosques y la costa californiana al norte de San Francisco. Me quedé fascinado escuchando a esos tres formidables escritores hablar de literatura mexicana. Sergio Pitol, que había vivido muchos años fuera de México, les hacía a las escritoras preguntas sobre personalidades y libros. Lo que para ellos fue una amena conversación de café, para mí fue una lección de literatura mexicana.

Lo vi una vez más para llevarlo al aeropuerto de San Francisco. Cuando lo recogí en el lobby de su hotel estaba leyendo un libro en ruso. Había aprendido varios idiomas eslavos durante una larga y distinguida carrera de diplomático en los países del Este. Había, además, traducido a Wiltod Gombrowicz, entre otros escritores polacos.

Me regaló tres libros suyos: Infierno de todos, Asimetría y El tañido de una flauta. Quedé deslumbrado por la lectura de El tañido de una flauta; la historia de un hombre que asiste al festival cinematográfico de Venecia, donde ve una película japonesa que le revela los datos que él desconocía de la historia de la muerte de un amigo suyo en México. El tono de la novela está en los primeros párrafos: «Más vivo y más cierto, se repite, el trato con fantasmas auténticos que con esos de carne y hueso con quienes ha pasado buena parte del día.» El pasado y la ficción irrumpen en el presente del personaje central como una amalgama de reflexiones y asociaciones; tema que él maneja magistralmente en otras obras de ambiente europeo, como en «Mephisto Waltzer», uno de sus mejores cuentos. Quedé tan entusiasmado con la lectura de El tañido de una flauta que leí inmediatamente el resto de sus obras.

$\mathrm{Su}$ primer libro, Infierno de todos (1963), recoge algunos cuentos que dan un poco la otra cara de la moneda del mundo de la revolución mexicana plasmado por Carlos Fuentes en La muerte de Artemio Cruz y más tarde en otros textos como Agua quemada. Mientras que Fuentes representa el surgimiento de una plutocracia que toma las riendas de la nación mexicana como consecuencia de la revolución, Pitol da atisbos reveladores de cierto sector de la antigua oligarquía desplazada por esa plutocracia.

$\mathrm{Su}$ mundo literario es un tejido de asociaciones y reflexiones que parten de anécdotas de las que salen textos que forman parte de otros textos, y que a veces pueden ser leídos independientemente del texto de 
origen. Es el caso del «Relato de Billie Upward», un trozo de la novela Juegos florales (1982), que aparece como texto aparte en Vals de Mefisto (también llamado Nocturno de Bujara en la edición mexicana de 1981) y se lee con total independencia de la novela, que sería otra sin el texto. La estética de la asociación cobra otra dimensión en $E l$ tañido de una flauta y otros relatos de ambiente europeo, cuando una obra de arte mencionada en el texto impacta algún personaje al revelarle datos sobre su propia vida.

Lo más novedoso en Pitol es la construcción del texto, que parte de anécdotas que llevan a un encadenamiento de asociaciones, hechas ya sea por el narrador, ya por los personajes. El encadenamiento de asociaciones empieza a constituir un mundo complejo de ambientes y de relaciones humanas al que uno ingresa con una facilidad engañosa.

Vi nuevamente a Sergio Pitol el verano pasado, gracias a las escritoras Jean Franco y Rosario Ferré. Ellas lo iban a visitar en la embajada de México en Checoslovaquia y me pusieron en contacto con él para que yo también lo visitara.

Tuvimos, en paseos prodigiosos por Praga y en camino a Marienbad, conversaciones inolvidables sobre su infancia en un ingenio azucarero en Veracruz y sobre su última novela, El desfile del amor. La entrevista intenta documentar lo conversado para servir de introducción a la vida y obra de este notable escritor latinoamericano.

EFRAín KRISTAL: Quisiera me dijeras algo sobre tus abuelos. ¿Cómo llegaron a México? ¿Cómo se integraron al mundo de los terratenientes? iSe inscribieron ellos en los círculos de las oligarquías antiguas, o más bien en grupos que apoyaban a Porfirio Díaz, por ejemplo? Me interesa saber también cómo les afectó la revolución mexicana.

Sergio Pitol: A Porfirio Díaz lo apoyaban tanto la antigua oligarquía como una nueva clase media, formada durante su administración. Mis bisabuelos maternos llegaron a México en la segunda mitad del siglo pasado y se instalaron, aunque nunca he entendido exactamente por qué, en una región muy apartada del estado de Veracruz, donde crearon cafetales y ganaderías. Mi bisabuelo materno, muy entusiasmado por los resultados que se estaban logrando en aquella región, convenció al presidente de la República, Manuel González, para que un grupo de colonos italianos se establecieran en esa misma región selvática y continuaran su labor. Era la época del positivismo en México y en América Latina; entonces, la idea de desarrollar nuevas zonas de riqueza, de crear ingenios azucareros, transformar la selva en campo cultivado, resultó muy 
apetecible. Se creó un compromiso de dar a costos reducidos terrenos muy grandes, que los colonos desbrozarían y en los cuales introducirían nuevos cultivos. También existía el proyecto de crear sederías, es decir, el cultivo del gusano de seda, la morera, para desarrollar esa industria en México. El gobierno aceptó las condiciones que ellos exigían, entre las cuales estaba la construcción de un ferrocarril que comunicaría esa región con la ciudad de Córdoba, Veracruz, que tenía acceso tanto al puerto como a la capital por ferrocarril y por carretera. Entonces, hacia 1881, después de múltiples incidentes, se logró hacer realidad aquel convenio entre el gobierno de México y un grupo de italianos que llegarían al país. Entre ellos se encontraba mi familia paterna. Hay un libro que apareció hace cuatro años, Los italianos en México, del padre Benigno Zilli, sobre este grupo, que me permitió enterarme de muchas cosas; sobre todo documentación que no conocía yo por tradición familiar. Las condiciones fueron absolutamente terribles, porque al atracar el barco que los transportó hubo un estallido de vómito negro y fiebre amarilla en Veracruz que aterrorizó a los recién llegados. No pudieron continuar el viaje; fueron internados en un lazareto cerca del puerto. Llegaron muy minados, muy desmoralizados a la región, pero lograron fundar la colonia Manuel González, que era el centro de reunión de todas estas familias. Les repartieron las propiedades, que fueron luego sus haciendas. Pero la imagen que tenían de la tierra prometida, de la ciudad rousseauniana, resultó completamente diferente a la realidad. Se trataba de un lugar muy abrupto, de tierras barrialosas, de animales e insectos que desconocían, como la nigua, que en todas las crónicas que he leído los enloquecía. Este insecto se mete en los pies y en las uñas y produce casos de locura y desesperación. Sin embargo, una parte de ellos se quedaron y crearon lugares portentosos de belleza. Fue una región muy próspera. La ciudad más próxima era muy hermosa: Huatusco, a la cual muchos de ellos se integraron. Huatusco marcaba el tono de la vida social de la región.

Era un lugar sumamente aislado. El compromiso del gobierno de crear un ferrocarril se quedó a la mitad; las vías férreas llegaron hasta San Juan Coscomatepec, a muchos kilómetros de la colonia.

Recuerdo que, cuando era chico, iba a visitar a mis familiares, y de Córdoba a Huatusco, un tramo que ahora se cubre en hora y media, hacíamos más de un día en trenes y coches. Demoraba más de un día para cruzar las barrancas que dividían o separaban esta región de todo lo poblado del estado. Quizá eso llevó a los colonos a vivir una vida bastante excéntrica. En algunas casas se leía mucho. Yo recuerdo, en casa de mi abuelo paterno, las tardes de lectura. Hacían música, crea- 
ron módulos muy diferentes a los de la región, tanto que a la distancia uno ve una población como las de la Lombardía o del Véneto. Una población metida entre la selva, de casas de campo con portales totalmente diferentes a los portales andaluces, que son los del resto del estado, donde se vivía, se imaginaba, con una inmensa nostalgia, a Italia. Cada ciertos años, mi familia materna hacía el viaje tradicional a Italia, donde los chicos pasaban algunos años de escuela. Algunos se casaban allá y luego regresaban con sus esposas. La vida iba a caballo entre el Véneto y estos ranchos, esta zona aislada de México.

E. K.: ¿Qué idioma se hablaba en la casa de tus abuelos?

S. P.: Hasta la generación de mis abuelos se hablaba normalmente el italiano y un pésimo español hecho a base de imperativos para hablar con peones y sirvientes. «Haz esto», «friega», «muele», etc. La vida idílica, en la que de alguna manera habían convertido este lugar salvaje después de una o dos generaciones, se hizo trizas por la revolución; ellos jamás pudieron comprenderla. No entendían el porqué del proceso, porque vivían muy incomunicados del resto del país. La revolución cortó el sueño utópico y segregacionista de ese estado dentro del estado en que vivían, e hizo que ya la generación de mis padres y de mis tíos fuera una generación criada en el español, porque la irrupción del exterior fue violenta. Entonces tuvieron que refugiarse temporadas largas, meses, a veces años, en la ciudad.

E. K.: Entonces el mundo de los Ferri que tú narras en El infierno de todos es un poco el mundo de tus abuelos.

S. P.: Claro. E1 mundo de los Ferri y de todos estos cuentos de mis primeros libros recoge de una manera unívoca estas historias 1legadas a mí por tradición oral, que se multiplicaban en la casa y se repetían constantemente. Mis padres murieron cuando yo era muy chico. Quien hizo el papel de madre fue mi abuela, que era una mujer que había vivido de manera muy directa este trastorno de la existencia. Los viajes a Italia se acabaron, desde luego. La vida en las haciendas se hizo peligrosa. Mi abuelo murió en su rancho porque no fue posible llevar de Huatusco a un médico que lo atendiera, o al menos se atribuía a eso su muerte. Entonces, el pasado en mi casa tenía mucho más presencia, mucho más vida entre mi abuela y las gentes de su generación, sus primas, sus cuñadas, que el presente. En las tardes conversaban sobre ese mundo bárbaro perdido ya para nosotros. Ese mundo nos resultaba exótico, ajeno, anacrónico, pero de alguna manera nos permeaba. Esto es lo que forma el cuerpo, la sustancia de mis primeros relatos. En cierta forma fue un medio de exorcizar todo ese mundo. Después de la revolución vino la reforma agraria, la pobreza, el desvencijamiento de la 
economía, de los moldes en que estaba sustentada la vida de estas familias. Esto también creó en mi infancia una opción: o estar con el mundo de ellos, o estar con el mundo de la escuela pública donde yo tenía que ir, y que era socialista, porque era el tiempo de Cárdenas. A pesar de mi existencia aparentemente esquizofrénica entre lo que aprendía en la escuela y lo que repetía en la casa, no recuerdo haber vivido esa dicotomía como problema, no recuerdo choque alguno entre ambos mundos. Más bien fue la Segunda Guerra Mundial la que creó durante un tiempo una especie de pánico en el mundo de la casa, porque de repente pasamos a ser la parte enemiga de la nación. Ya no solamente éramos la clase derrotada, sino además una porción del enemigo. Eramos italianos incrustados en México. Nosotros vivíamos ya para aquel entonces en la región de Potrero, otra parte de Veracruz que era de haciendas cañeras e ingenios donde la mayor parte de los propietarios. eran americanos, alemanes, españoles. Me parece que nosotros éramos los únicos italianos. Ese mundo respiraba el habla del Golfo y las costumbres del Caribe. El mundo de Potrero fue el verdadero mundo de mi infancia, muy distinto del de mis abuelos, bisabuelos, tatarabuelos metidos en la selva, adonde íbamos una vez por año, durante las vacaciones. Allí todo era más moderno, más apegado a la civilización: los baños se calentaban con electricidad. Las cocinas de leña y carbón eran impensables allí. Todo era eléctrico. Pero también era un mundo de propietarios extranjeros o de origen extranjero. Los vínculos de propiedad hacía que americanos, italianos y alemanes se entendieran muy bien. Había un club de damas, adonde iban los jueves las señoras a jugar al bingo. Los hombres jugaban cricket o tenis. Era de nuevo un mundo dentro de otro mundo que repetía aquel al que nosotros íbamos una vez. año y que nos parecía muchísimo más anacrónico.

E. K.: ¿Cómo te separaste de ese mundo y llegaste a la ciudad de México?

S. P.: La escuela, de alguna manera comenzó a alejarme de ese mundo porque me daba muchos elementos más. Luego, era un mundo muy insalubre. El paludismo era endémico en la región y yo fui un niño palúdico. Tuve que pasar muchos meses en cama, en lugares oscuros, o con una lámpara, leyendo. A los diecisiete años, cuando terminé los estudios de secundaria, me fui a la ciudad de México. No me era ajena la ciudad, porque íbamos con frecuencia a visitar familiares. Quedaba a un día de viaje. Era un lugar posible y maravilloso. Yo me sentía muy ligado al mundo de Veracruz, del trópico. Durante mis años universitarios pasaba allí fines de semana largos y las vacaciones íntegras. Sabía apreciar el trabajo de campo, la vida de campo. 
E. K.: Me parece curioso que no hayas vivido ese mundo como algo contradictorio.

S. P.: Bueno, no lo vivía como drama, ni como conflicto, pero no dejaba, ya al llegar a la adolescencia, de sentir sus tensiones. En la infancia, de alguna manera consideraba que la vida era así; que ésa era la vida de todos los adultos. El momento quizá en que llegué a sentir cierto temor infantil de quedarnos en la inopia, de perder todo asidero, fue durante la guerra. Muy cerca de donde vivíamos se crearon campos para recluir a los alemanes sobre los que se tuviese alguna sospecha de deslealtad a la nación. A muchos de mis familiares los obligaron a ir a México a un sitio especial en lo que era el deportivo italiano, a que revisaran sus papeles, sus antecedentes. Todo esto, aun siendo nietos (mi abuela era nieta) de los que habían venido. Pero el haber pasado sus infancias en Italia, donde se quedaban largas temporadas, y el que se consideraran italianos, no los ayudaba. Esa situación hizo que de repente pasara por mi casa mucha gente, parientes que tenían que ir a México, en un clima de exasperación y de temor. Pero luego el cine lo resolvió todo, porque en las películas de guerra esos problemas se volvían algo ficticio, algo para construir juegos de niños, donde decidíamos quiénes eran los del Eje y quiénes eran los aliados, y hacíamos simulacros de lucha. De ese modo, la realidad se convirtió también en un material ficticio.

Eran los mayores quienes necesariamente sufrían estas contradicciones. En parte por el deterioro grave de nuestra situración económica. Estábamos sostenidos por un prestigio de clase, pero en realidad vivíamos muy cerca de la pobreza. Los inviernos íbamos todavía al balneario de Tehuacán a tomar las aguas; teníamos sirvientes, eso sí; pero los ranchos estaban en plena bancarrota en esa época de mi infancia. En los adultos, en sus conversaciones, yo advertía su imposibilidad de incorporarse al presente. Siempre estaban en el pasado, en Italia, en la moda de otra época, mientras que el presente se reducía a familias divididas, ranchos tomados, malas administraciones que se adjudicaban a esa para ellos incomprensible nueva situación social. En mis cuentos recojo los conflictos tal como los adultos los contaban, aunque yo, de chico, no sentía su patetismo.

E. K.: ¿Cómo te integraste a la vida literaria de México?

S. P.: Cuando me fui a México llevaba una enorme carga de lecturas. Pasaba mis vacaciones en los ranchos de mis abuelos paternos, y mi abuelo era un gran lector, hacía música, leía partituras. En su casa siempre había libros. También mi abuela materna era una lectora de tiempo completo. Esa abundancia de lecturas que formaba parte de 
la vida cotidiana y el hecho de que yo, a causa de mi mala salud, no pudiera disfrutar como mi hermano, como mis primos, de una vitalidad que les permitía mucho más acción física que a mí, me marcaron definitivamente. Eran lecturas muy variadas, como el Tesoro de la Juventud, libros de viajes a países extranjeros, cuyas láminas todavía puedo recordar como si las estuviera viendo, y La guerra y la paz en los seis volúmenes de la edición mexicana, así como una serie de novelas rosas que le leía a una señora amiga de mi abuela que estaba casi ciega. Había visto también mucho cine en Potrero. Unos americanos tenían un aparato de cine y hacían funciones de buena parte del repertorio de los años treinta, que para mí es el cine que sigue estando vivo.

Cuando llegué a México estudié leyes porque era la carrera más próxima a las letras. Tenía muy poca idea de los estudios que se llevaban a cabo en la Facultad de Filosofía y Letras de la UNAM. En el mundo de Veracruz sólo había abogados, médicos e ingenieros; químicos también, porque eran necesarios en los ingenios. Estudié derecho porque en mi mente era lo único que asociaba con la literatura. Sabía que muchos de los escritores mexicanos que admiraba, como Alfonso Reyes o José Vasconcelos, habían hecho la escuela de derecho y de alli habían pasado a la literatura.

E. K.: ¿Cuándo leíste Pedro Páramo? ¿Y qué es lo que significó para ti esa lectura?

S. P.: Lo leí en el momento mismo de su aparición. Fue emocionantísimo porque descubrí un lenguaje distinto al de la literatura a la que yo estaba acostumbrado. Encontré en Pedro Páramo una similitud con el mundo que yo había dejado atrás: todos esos derrumbes de familias, de ranchos, de vidas. En el mundo de Rulfo se vive de recuerdos; es un mundo de muertos vivos muy semejante al que yo había dejado en la infancia, aunque el escenario era otro. El de nosotros era más plácido, más sensual, por estar ubicado en el trópico. Ningún drama era allí del todo un drama, como lo es en los desiertos que describe Rulfo. Para entonces había leído mucha literatura europea y contemporánea. También en Córdoba, en mis estudios secundarios, me había obligado a leer en francés y en inglés. Recuerdo haber intentado leer entonces el Ulyses de James Joyce en la biblioteca de uno de mis amigos de escuela, hijo de Jorge Cuesta, uno de los poetas del grupo de Contemporáneos. Sentía que la prosa extranjera era de una calidad o de una textura distinta a la de los autores en lengua española. En la poesía nunca sentía las discrepancias, porque la poesía mexicana se podía comparar con la poesía más moderna de esos momentos. Pero en la narrativa el ritmo era muy distinto. Los elementos de la literatura en español eran tan tradi- 
cionales, que a menudo uno sentía cierto aire rancio y pueblerino. De repente, Pedro Páramo fue para mí el enlace entre la narrativa mexicana y la mejor literatura extranjera.

E. K.: Así también lo vivieron otros escritores mexicanos amigos tuyos.

S. P.: Yo creo que para toda mi generación fue un poco lo mismo. Por esa época apareció también La región más transparente de Fuentes, llena de cosas nuevas, de elementos que uno había advertido en Lawrence o en Dos Pasos, pero que los jóvenes lectores de entonces no hubiésemos esperado de la narrativa en español. En ese tiempo, además, leí un cuento de Borges que fue para mí uno de los momentos verdaderamente nupciales de mi trato con la literatura. Los libros de Borges apenas circulaban en México, y sólo un grupo muy reducido de entusiastas seguía su obra. Un grupo que yo conocía, exclusivísimo, que se hacía 1legar sus libros desde Buenos Aires. Recuerdo que en esos años, debe de haber sido el 51, en uno de los viajes que hacía de Córdoba a México, el autobús se detuvo en Tehuacán y me bajé a comprar el periódico. En El Suplemento de Novedades, que en esa época dirigía Fernando Benítez, había un texto de José Durand, ahora profesor en Berkeley, sobre dos narraciones fantásticas, una de Lugones y la otra de Borges: «Los caballos de Abdera» y la «Casa de Asterión». Leí la nota de Durand, que me interesó y luego pasé al cuento de Borges; me produjo una alucinación total. Llegé a mi casa horas después habiéndolo releído varias veces. Fue como descubrir la verdadera lengua castellana.

E. K.: ¿Fue después de esa experiencia que empezaste a escribir?

S. P.: Sí. Siempre estuve seguro de que escribiría, pero pensaba que lo que haría sería teatro. Desde niño me había gustado mucho el teatro; las únicas veces que recuerdo haberme escapado de la escuela fue para ir a Orizaba, una ciudad vecina, donde algunas compañías teatrales de México hacían temporadas. Ir a México, para mí significaba fundamentalmente ver piezas de teatro. En aquella época descubrí también que existía la Facultad de Filosofía y Letras y que ésta tenía un ambiente magnífico, donde hice muchos amigos. Tenía horas suficientes como para tomar clases optativas, ir de oyente a muchos cursos sobre historia del arte, sobre historia e historiografía, filosofía, literatura. Tomé entonces un curso, con Luisa Josefina Hernández, de técnica dramática. En su clase empezábamos a ver a los griegos y a estudiar sus cánones, la forma en que se arma un drama. Ella nos exigía, por ejemplo, después de estudiar a Esquilo, que hiciéramos un texto dramático sobre alguno de sus temas situado en nuestro tiempo. Yo me iba a mi casa a hacer mi tarea: fijaba los personajes, los ubicaba. Era casi siempre en los lugares 
que conocía, en los ranchos de Veracruz. Determinaba todas las escenas, y cuando empezaba a escribir, en lugar de una obra dramática me salía un cuento. Esa fue la manera en que empecé a escribir.

Los primeros cuentos que integran Infierno de todos son cuentos situados hacia el final de la revolución, sobre familias que sobreviven a ella o que se forman dentro de ese movimiento social. Lós personajes son generalmente niños que ven sin entender lo que pasa a su alrededor y que tratan de liberarse de obsesiones familiares. De alguna manera, como decía antes, creo que ese libro fue escrito para exorcizar un pasado que comenzaba a pesarme en demasía.

E. K.: ¿Cómo encuentras la voz que narra tus relatos?

S. P.: En los cuentos generalmente obedezco más que nada al estímulo que me produce una frase, un tono de voz determinado, en el que sigo pensando durante varios días hasta que lo desecho o, en su caso, creo un cuento. En la novela es mucho más difícil; intervienen muchos más elementos. Hay la creación del tiempo, que es muy difícil sostener con un solo tono de voz o con la misma modulación. Una vez que tengo ciertas ideas, cierta temática ya más o menos cercada, es decir, el material sobre el que voy a trabajar, puedo imaginar las escenas fundamentales. A veces es el final o alguna escena intermedia que tengo muy clara, muy definida en cuanto a los efectos cómicos o dramáticos que en ella se van a producir. Allí el problema fundamental es definir quiénes son los personajes, qué hacen en la vida. Y luego empezar a buscar la voz de esos personajes. Una vez que la tengo, la estructura casi se organiza sola. Para mí, la novela es fundamentalmente un problema de estructura. Y la estructura me la dicta cierta música verbal que necesito oír: la voz, el tono, los tics lingüísticos de los personajes.

E. K.: En un artículo que escribiste sobre Kuśniewicz dices que para él «narrar una historia equivale a encontrar las notas con que se forma una melodía». ¿Hasta qué punto sientes tú alguna afinidad con esa estética?

S. P.: En varias partes de su novela magistral, el Rey de las dos Sicilias, Kuśniewicz va buscando ciertas notas que logren formar la melođía. El protagonista, oficial del regimiento de húsares del batallón de las Dos Sicilias, trata en su diario íntimo de entender su vida, de liberarse del peso abrumador de culpa que lo abruma, señalando siempre esa necesidad de encontrar las notas que le permitan crear un todo, en el que se sienta explicado o liberado. El Rey de las Dos Sicilias, para mí, fue una revelación. Creo que es una de las novelas más extraordinarias que se han escrito en los últimos años, y encontré que su poética, en cierta forma, definía muchas de mis aspiraciones formales. El hurgar 
melódicamente en distintas partes hasta que la melodía se incorpora a la narración de manera integral, por ejemplo.

E. K.: Entonces, ¿la creación del ambiente es posterior a la búsqueda: de la yoz?

S. P.: No. Gran parte ya está dado previamente; tengo fijado el momento histórico; he visto fotografías de ropa, coches, objetos de la época; he leído abundantemente sobre el tema que me interesa. Hago muchas notas, leo libros de historia, memorias de ese período. Veo, sobre todo, la prensa de la época y fotos. Por ejemplo, existe en México el archivo Casasola. En él se reproduce la historia del México contemporáneo a través de fotografías hechas por la familia Casasola. Aquí, en mi oficina, tengo un volumen que es una síntesis de ese archivo, que te da año por año lo que sucedió, qué obras de teatro se estrenaron, qué libros aparecieron, qué acontecimientos políticos sociales se produjeron, desde los más triviales hasta los verdaderamente importantes. Ese texto está acompañado por una profusión de fotografías. Meterme en esas fotografías es quizá la parte que más me nutre. Ver cómo se vestían las señoras cuando iban al hipódromo, quiénes se reunían en tal café, cómo se bailaba. Fotos de restaurantes, carteleras de teatro. Entonces tengo toda esa historia menuda que me hace sentir vivos a los personajes que voy imaginando; verles ya su ropa, sus coches, los restaurantes a los que van, etc., sin dejarme tampoco vencer por el peso de una falsa erudición, porque no es ése el tipo de novela que yo trabajo.

Así que primero tengo los temas. Por ejemplo, de regreso de Berkeley, donde nos conocimos, en un hotel de San Francisco hice las primeras notas para $E l$ desfile del amor. Quería escribir una novela policíaca que tuviera como escenario un edificio de finales del siglo pasado, en que viví en la Colonia Roma, que es un monumento a la excentricidad. Ese edificio me parecía extraordinariamente novelesco, porque todos los pasillos dan a un gran patio; de manera que si alguien quisiera observar a los demás desde cualquier punto del edificio, podría siempre darse cuenta de quién entraba a visitar a quién, a qué horas salían de tal departamento. Me parecía un marco perfecto, un escenario ideal para una novela policíaca. En ese tiempo me preocupaba mucho otra cosa. Había yo estado viviendo en México después de muchos años pasados en el extranjero. Me interesé mucho por viajar por el país dando conferencias y lecturas. A veces lo hacía con Margot Glanz, a veces solo, y recorrí muchos puntos del país, una experiencia para mí notable porque me permitió reintegrar muchas imágenes y recoger otras de lugares que no había visto nunca; la experiencia que me producían estas lecturas con públicos regionales era de 
un gran desconcierto ante la ignorancia de las nuevas generaciones sobre cosas que para mí eran absolutamente sabidas e inmediatas, y que veinte o treinta años antes cualquier joven en México las habría conocido. Advertí que la erosión de la memoria histórica, producida quizá por el desarrollo demográfico tan acelerado de México, por el dinamismo del país, pero sobre todo por la enorme frontera con los Estados Unidos y la difusión a través de la televisión, radio, cine y prensa desde Estados Unidos de otra cultura, le borraban al mexicano la visión real de su historia. Estábamos hablando del período de Obregón, por ejemplo, y alguien por ahí hacía una pregunta. Contestaba yo algo que me parecía evidente que debía ser del conocimiento común de los oyentes, y me encontraba, de repente, con que la mayoría no sabía nada al respecto. Eso me hizo sentir la necesidad de escribir una novela que fijara ciertos momentos históricos del país, una novela no histórica en el sentido clásico del término, pero que indujera al lector a buscar otras referencias sobre la época tratada.

E. K.: En El desfile del amor está muy presente que la labor del novelista, o quizá del cronista del pasado, es de presentar la visión privada de la historia y no la visión oficial.

S. P.: Bueno, a mí me interesa fijar en esa novela ciertos hechos históricos, al ver el desconocimiento existente de la historia reciente, ya no se diga de la lejana. Ante la alarma que me produjo ver ese desgaste del conocimiento histórico, fijo mi historia en un tiempo determinado, donde quiero situar a personajes que representan un sector específico del espectro social. La novela trata de un hecho real, que es el movimiento de la derecha radical ligada al fascismo poco después de la Guerra Civil española y en los principios de la Segunda Guerra Mundial. En ese sentido, los datos que presento son verdaderos, históricos. Ahora bien, la trama se libera de esa «verdad» y no trata de investigar la historia ni de crear una teoría de la historia. Las versiones son contradictorias porque todos los personajes tienen algo que esconder. A1 lector le incumbe descubrir, o intuir, qué es lo que ocultan y por qué lo hacen.

E. K.: Lo que subrayas en tu libro no son los sucesos claves del devenir histórico que explicarian el presente de ciertos sectores de las clases acomodadas de México, sino más bien la vida privada de esas personas. Tu novela podría considerarse el reverso del tapiz de ese devenir histórico.

S. P.: En eso estoy totalmente de acuerdo. Mis personajes están situados en un año que viene a ser el resultado de otro fenómeno histórico, que es la revolución. Hay un capítulo que se llama la clase derro- 
tada, o algo parecido, que se refiere a la aristocracia porfiriana. En el 42 esta clase vive aún en la pobreza; no ha reconquistado el poder ni se ha incorporado al nuevo orden. Vive en un maremágnum de confusiones. Otros personajes como Delfina Uribe, la dueña de la galería de arte, son hijos de la revolución. Sus padres fueron dirigentes revolucionarios. Quizá por eso tiene tanta importancia el año 1914, fundamental en el destino de la revolución. Del lado de esa época salen todos los polvos del año 1942. En la novela, la trama misma, la narración, trata de desprenderse del rigor histórico, pero teniendo siempre presente - pues eso me interesaba mucho- que de alguna manera le comunicara al lector cierta curiosidad, cierta palpitación sobre lo que ha ocurrido en México a lo largo del siglo.

E. K.: ¿Cómo se te ocurrió el recurso del historiador como núcleo de la historia?

S. P.: El recurso del historiador fue muy simple. Tenía yo ya los personajes más o menos ubicados, los dos grandes grupos de opuestos: los hijos de revolucionarios famosos y los hijos de los aristócratas. Había más o menos precisado el acontecimiento criminal, el motor de la novela policíaca, el asesinato de un joven austríaco a la salida de una f́iesta del edificio donde se ubica la novela. Tenía muchos de los personajes ya imaginados, de algunos de ellos, Emma Werfel, por ejemplo, había encontrado ya hasta la voz. De pronto me di cuenta de que para que ese material humano pudiera coincidir de la manera más o menos ligera que yo quería darle a la novela, un ritmo casi de vaudeville, necesitaba un personaje que pudiera transitar entre todos estos círculos con una naturalidad total. Al principio pensé que podría ser un periodista, podía ser un inspector policíaco, pero entonces me veía metido en el mundo sórdido de la policía mexicana de esa época y hubiera sido otra novela, y el personaje no hubiera tenido el lenguaje adecuado para hablar con la directora de una galería, con un pintor, con un crítico. Entonces, eliminando posibilidades, apareció un historiador, que además da la clave de esos distintos períodos que se mueven.

Ahora, los libros de historia que este escritor escribiría no creo que fuesen diferentes a los de la versión oficial en la que se integra. Lo que a él le interesa en el momento que llega a México, al encontrar ciertos datos que le recuerdan su infancia, es la pequeña historia. El, en ese momento, trata, aparentemente, de desinteresarse de una investigación y empieza, como por juego, por divertimento, a veces con mucha irritación, a veces con placer, a encontrar los móviles de un crimen que sucedió en el mismo edificio en que él había vivido muchos años atrás, entre gentes que conoció y algunos de los cuales eran parientes 
suyos muy cercanos. Allí utiliza otra clave, una clave muy menor. No quiere teorizar sobre la historia ni buscar causas, ni siquiera saber hasta dónde el hecho que le interesa está engarzado en la Historia, con mayúscula; él tratará ese hecho casi como un acontecimiento personal. El personaje es por ello un medio, un instrumento absolutamente estructural.

Por ser pariente de algunas personas puede tener el acceso a información que yo no hubiera podido conseguir de otro modo. Este personaje está tratado, además, con cierta ironía: es un investigador que no descubre nada, es un historiador que se da muy pronto por vencido; sin embargo, en su fracaso nos permite a mí y a los lectores ver un friso general de la sociedad mexicana en dos distintos momentos. En el 70, cuando llega de Inglaterra, y en el 42, cuando era niño, el año que empieza a investigar.

E. K.: Por lo que acabas de decir, supongo que la elaboración del tiempo en la novela no te fue problemática.

S. P.: La estructura se vuelve muy sencilla en esta novela una vez que tiene uno al historiador como la persona que va a recorrer las distintas instancias. Es una estructura como la de un reloj: son doce capítulos que responden a los doce personajes que van a ser visitados y entrevistados por el historiador. Es, por otro lado, la estructura de novela policíaca clásica; la estructura, en cierta forma, de Las almas muertas; toda proporción guardada. Determinados sitios aparentemente ajenos entre sí son vistos por alguien que logra establecer sus conexiones secretas. Si no es posible descubrir los resultados de su investigación, por lo menos se sabe que hay una conexión entre todo ese mundo al que hace circular. Fue un recurso que me dio una facilidad enorme. Si el narrador no hubiera sido un historiador, la novela habría tenido una estructura completamente diferente.

E. K.: Me parece que en los personajes hay una especie de teatralidad que muchos de tus personajes en otros cuentos y novelas comparten. Me parece, además, que el tema de la ópera es un tema recurrente y que es un recurso para presentar, de una manera oblicua, tragedias muy profundas.

S. P.: Creo que es mi deuda con el barroco. Con elementos aparentemente muy lineales, muy despojados de prestigio y grandeza, se van creando ciertos rasgos extremos, cierta radicalidad de movimientos muy operísticos y que obedece quizá a una de las necesidades del barroco. Llevar la emoción a su mayor tensión. Expresar, a través del gesto, el rostro y la máscara a la vez. 